\title{
The Prevalence and Magnitude of Job Insecurity
}

\author{
Leigh-Anne Paul Dachapalli \\ Department of Human Resource Management, UNISA \\ Sanjana Brijball Parumasur \\ School of Management Studies, University of KwaZulu-Natal
}

Accepted: Junie 2012

This study investigates the prevalence and magnitude of job insecurity experienced by employees in an organisation undergoing major transformation, while taking cognisance of intercorrelations among its subdimensions. The research adopted a formal, hypothesis-testing approach whereby quantitative data was collected using a cross-sectional survey method from a sample of 1620 employees. The findings indicate that threats to salient job features/total job and feelings of powerlessness trigger the potential for job insecurity. This study identifies conditions that increase the potential for job insecurity. Recommendations are presented for reducing the prevalence and magnitude of job insecurity.

Key words: job insecurity, job threats, powerfulness, powerlessness, importance of job features, total job

JEL: 1280,630

\section{1}

\section{Introduction}

South Africa is undergoing tremendous changes in the political, economic, legal, social and educational environments. Working life has been subjected to dramatic change over the past decades as a result of economic recessions, new information, technology, industrial restructuring and accelerated global competition (Hartley, Jacobson, Klandermans \& van Vuuren, 1991; Hellgren, Sverke \& Isaksson, 1999). As a consequence, organisations have been forced to engage in various adaptive strategies in order to address new demands and remain vigorous in this unpredictable environment. Organisations have two options if they wish to become more profitable; they can either increase their gains or decrease their costs, often by reducing the number of employees (Burke \& Cooper, 2000; Burke \& Nelson, 1998; Tetrick \& Quick, 2003). These organisational options often surface in actions like outsourcing and privatization, often in combination with personnel reductions through layoffs, offers of early retirement and increased use of sub-contracted workers (Burke \& Cooper, 2000; Burke \& Nelson,
1998; Tetrick \& Quick, 2003). The changes in South Africa have impacted tremendously on organisational structures and have created a continuous need for organisational changes in terms of retrenchments, rightsizing, mergers and acquisitions and downsizing. As a result of these organisational changes, job insecurity has emerged as one of the most important issues in working life and has brought the issue of insecure working conditions into the forefront (Sverke, Hellgren \& Näswall, 2002).

Organisational restructuring/downsizing has had a tremendous effect on employees' health. Bohle, Quinlan and Mayhew (2001) concluded that 88 per cent of studies undertaken investigating the impact of organizational restructuring found a measurable negative effect on health in at least one of a range of measures, such as the increased risk of work-related injury, occupational violence, cardiovascular disease and psychological distress or mental illness. In addition, Mohren, Swaen, van Amelsvoort, Borm \& Galama, 2003) found a relationship between job insecurity and common infections and health problems. Furthermore, studies deduce that the characteristic effects of downsizing, that is, job strain and job insecurity, have resulted in 
higher levels of mental and physical health problems (Kim, 2003; Kivimaki, Vahtera, Pentti, Thomson, Griffiths \& Cox, 2001; Mauno, Kinnunen, Makikangas \& Natti, 2005; Pepper, Messinger, Weinberg \& Campbell, 2003; Strazdins, D'Souza, Lim, Broom \& Rodgers, 2004). Repeated rounds of downsizing/ restructuring (Quinlan, 2007) and job insecurity have been found to result in negative and longterm symptoms of distress (Isaksson, Hellgren $\&$ Pettersson, 2000) and work/family conflict and burnout, including crossover burnout (Westman, Etzion \& Danon, 2001). Evidently, restructuring/downsizing creates volatility in the job market and is a threat to both stable and long-term relationships between employers and employees, as well as to their well-being. Hence, this study aims to:

- investigate the prevalence and magnitude of job insecurity on the part of employees in an organisation undergoing major transformation; and

- assess whether significant intercorrelations exist among the sub-dimensions of job insecurity (the importance of job features, the existence of job features, perceived threats to job features, the importance of the total job, perceived threats to the total job and feelings of power/powerlessness). In other words, the study aims to determine the strength and direction of the relationships among the sub-dimensions of job insecurity.

\section{2}

\section{Literature review}

\subsection{The definition and nature of job insecurity}

Job insecurity is situated between employment and unemployment because it refers to employed people who feel threatened by unemployment (Hartley et al., 1991). Job insecurity has been conceptualised from two points of view, that is, as a global or as a multidimensional concept. Greenhalgh and Rosenblatt (1984) define job insecurity as a feeling of powerlessness to maintain desired continuity in a job situation that is under threat. Job insecurity has been defined according to a global viewpoint, signifying the threat of job loss and job discontinuity (Caplan, Cobb,
French, van Harrison \& Pinneau, 1980; De Witte, 1999). Hence, job insecurity is said to be both an individual's negative expectations about continuity in their job situation (Davy, Kinicki \& Scheck, 1997) and their perception of a potential threat to continuity in their current job (Heaney, Israel \& House, 1994). This definition has been applied in the context of organisational crisis or change in which job insecurity is considered as a first phase of the process of job loss (Ferrie, 1997). Researchers adopting a multi-dimensional definition of job insecurity argue that the term refers not only to the degree of uncertainty felt or experienced by the employee, but also to the components of job insecurity:

- The severity of the threat concerning job continuity or aspects of the job.

- The importance of the job features to the individual.

- The perceived threat of a totally negative effect on the job situation.

- The total importance of the organisational changes.

- The powerlessness and inability of the individual to control the above components.

Likewise, Hellgren et al. (1999) differentiated between two different forms of job insecurity: quantitative job insecurity, which is worrying about losing the job itself, and qualitative job insecurity, which is worrying about losing important job features. While quantitative job insecurity is related to the general comprehensive operationalisation of the construct, qualitative job insecurity refers to feelings about potential loss of quality relating to the organisational position, such as the deterioration of working conditions, the lack of career opportunities and decreasing salary development (Sverke \& Hellgren, 2002).

The underlying theme contained in the various definitions is that job insecurity is a subjective phenomenon, meaning that it is based on the individual's perceptions and interpretations of the immediate work environment (Hartley et al., 1991). Job insecurity refers to the anticipation of this stressful event in such a way that the nature and continued existence of one's job are perceived to be at risk, the implication being that the feeling of job insecurity occurs only in 
the case of involuntary job loss. Two main themes identified in job insecurity are differentiated by Borg \& Elizur (1992) as being:

- Cognitive job insecurity, which refers to the likelihood of job loss.

- Affective job insecurity, which refers to the fear of job loss.

\subsection{The occurrence and degree of job insecurity}

In this study, the main aim is to investigate the prevalence and magnitude of job insecurity experienced by employees in an organisation undergoing major transformation. The prevalence and magnitude of job insecurity will be assessed in terms of the multi-dimensional definition of job insecurity. Researchers, like Greenhalgh and Rosenblatt (1984), who hold this view, believe not only that job insecurity is more than the perceived threat of job loss but also that it includes thoughts about losing valued job features, such as pay, status, opportunity for promotion and access to resources. Hence, in this study, job insecurity represents the interaction of three factors: (1) the threat to job features; (2) the threat to the entire job; and (3) the degree to which individuals perceive themselves to be powerless in counteracting threats to job features and the entire job or the work situation. These individuals further see the threats to the entire job as more severe than the threats to the job features, because one can lose one's job features but still maintain organisational membership. However, the loss of the entire job entails potential loss of career advancement (Greenhalgh \& Rosenblatt, 1984). Threats to the entire job and threats to job features correspond to what Hellgren et al. (1999) refer to as quantitative job insecurity and qualitative job insecurity respectively.

\subsection{The dimensions of job insecurity}

In this study, it is maintained that in order for qualitative job insecurity to take place, individuals must attach importance to the job features and must regard the existing job features as salient. In this study, the dimensions of job insecurity therefore include:

- The importance of job features: This determines the salience of job features such as pay, status, opportunity for promotion, access to resources, career opportunities, and position within the organisation;

- The existence of job features: This refers to the extent to which the salient job features exist in the organisation;

- Perceived threats to job features: This refers to the estimated likelihood of losing salient job features and feelings that important job features are being threatened;

- Importance of the total job: This determines how salient the total job is to the individual;

- Perceived threats to total job: This refers to either the estimated likelihood of the job itself being at risk or to perceptions of losing the job;

- Feelings of power/powerlessness: For example, during a process of transformation individuals do not know how to protect themselves and the sense of powerlessness or being unable to secure their future intensifies the insecurity they experience.

\subsubsection{Perceptions of job features}

Hellgren et al. (1999) found that the importance of job features significantly related to the features' actual existence. Greenhalgh and Rosenblatt (1984) indicated that job features are as important as the total job because loss of the former represents aspects of job insecurity but their loss would be less severe than losing the total job. Yousef (1998) concluded a significant and inverse correlation between the importance of job features and perceived threats to them. Brun and Milczarek (2007), like Chovwen and Ivensor (2009), found a significant relationship between the existence of job features and perceived threats to job features, such as position within an organisation or career opportunities. This reveals that, although the job features do exist, individuals perceive threats to these job features as a result of the restructuring that is taking place in the organisation. Chovwen and Ivensor (2009) and Ito and Brotheridge (2007), unlike Ugboro and Obeng (2001), found a significant relationship between power/ powerlessness and perceived threats to them.

\subsubsection{Perceptions of total job}

Ugboro and Obeng (2001) found that the relationship between perceived threats to job 
features and perceived threats to the total job were directly significant. This indicates that as threats to job features increase so do the threats to the total job; however, the threats to job features and to total job were not related to power.

\subsubsection{The consequences of job insecurity}

Since job insecurity involves the experience of a threat, and implies a great deal of uncertainty as to whether individuals keep their jobs in the future, it has been described as a stressor (Barling \& Kelloway, 1996; De Witte, 1999). Like other work-related stressors, job insecurity is associated with a number of detrimental consequences for both the individual and the organisation. The perception of job insecurity is frequently linked to reduced organisational commitment (Borg \& Elizur, 1992; Forbes, 1985), job satisfaction (Lord \& Hartley, 1998), job involvement (Sverke et al., 2002), job performance and productivity (Dunlap, 1994), work effort (Brockner, Grover, Reed \& De Witte, 1992) and to lack of trust in management (Ashford, Lee, Bobko, 1989; Forbes, 1985; Romzek, 1985) and intentions to leave the organisation (Ashford et al., 1989; Davy et al., 1997; Greenhalgh \& Rosenblatt, 1984). Job insecurity is also associated with decreased safety, motivation (Borg \& Elizur, 1992; Greenhalgh \& Rosenblatt, 1984) and compliance, increasing the risks of workplace injuries and accidents (Probst \& Brubaker, 2001). Evidently, job insecurity is consistently associated with lower levels of relevant job attitudes and behaviours.

Furthermore, job insecurity is also associated with higher levels of burnout, anxiety and depression and psychosomatic complaints (Hartley et al., 1991). The component of uncertainty inherent in job insecurity makes it a potent work stressor (Mauno \& Kinnunen, 1999). The lack of predictability or knowledge of what is to come with reference to the present job would give rise to distress for the individual. Several research studies have suggested that job insecurity should be related to different negative attitudinal, health-related and behavioural outcomes (Ashford et al., 1989; Dekker \& Schaufeli, 1995; Heaney et al., 1994; Hellgren et al., 1999; Probst, 2003; Sverke et al., 2002; Sverke \& Hellgren, 2002).
In terms of attitudinal outcomes, for example, De Witte (1999) states that job insecurity has a significant negative influence on the emotional well-being of the individual. It reduces the level of job satisfaction and leads to healthrelated outcomes such as psychosomatic complaints. Prolonged job insecurity is more detrimental and acts as a chronic stressor which has the potential to result in more potent negative effects as time progresses and may lead to behavioural outcomes like absenteeism (Dekker \& Schaufeli, 1995), thereby emphasizing the importance of the early identification of its occurrence.

Undoubtedly, the increasing antecedents and the detrimental consequences (individual and organisational) of job insecurity necessitate the study of the prevalence and magnitude of job insecurity in an organisation undergoing major transformation so as to attempt to reduce its occurrence and/or negative effects in the future.

\section{3}

\section{Research design}

\subsection{Participants}

The target population for this study consisted of 8341 employees from a telecommunication company, selected because it was undergoing major transformation. It was therefore expected that job insecurity would prevail. The population was made up of employees from the Gauteng and KwaZulu-Natal provinces. A sample of 1620 employees was drawn from both regions, using a probability sampling technique, simple random sampling, whereby subjects were extracted using a random number selection process. According to Sekaran (2003), the corresponding minimum sample size for a population size of 8341 is 367 , confirming that the sample size of 1620 is more than adequate for the study. The adequacy of the sample for conducting Factor Analyses was further determined using the Kaiser-Meyer-Olkin Measure of Sampling Adequacy for the measurement of Job Insecurity (0.914) and Bartlett's Test of Spherecity (66210.340; $\mathrm{p}=$ 0.000 ), which respectively indicated suitability/ adequacy and significance. The results indicate that the normality and homoscedasticity preconditions have been satisfied. 


\subsection{Measuring instruments}

Data was collected using an adapted version of Ashford, Lee \& Bobko's (1989) measuring instrument to assess the level of job insecurity. The questionnaire consisted of two sections. Section 1, which aimed to obtain a profile of the respondents, included biographical data relating to age, tenure, race, number of years in the current position, educational level, gender and region, and was measured on a nominal scale. Section 2 assessed the level of job insecurity. Section 2 consisted of structured questions using closed-ended questions relating to six sub-dimensions ( $2 \mathrm{~A}$ to $2 \mathrm{~F}$ ) of job insecurity:

- the importance for the individual of job features relating to opportunities for promotion, freedom to schedule one's own work and current pay (Section 2A, 17 items);

- the existence of job features that encompass perceptions of the extent to which the individual believes that the salient job features exist in his/her job (Section 2B, 17 items);

- perceived threats to job features that relate to the individual's fear that his/her job features will be under threat in the process of change (Section 2C, 17 items). The greater the extent to which the individual perceives job features to be threatened, the greater the job insecurity;

- importance of the total job in terms of the individual's current job (Section 2D, 10 items);

- perceived threats to the total job which encompass the individual's fear that his/her job will be under threat in the process of change (Section 2E, 10 items); and

- power/powerlessness encompasses an individual's ability/inability to counteract the threats (Section 2F, 3 items). Those who are high in power or low in powerlessness should not experience much job insecurity.

These sub-dimensions were measured on a 1 to 5-point itemised scale ranging from very unimportant (1) to very important (5) and a 1 to 5 point Likert scale ranging from strongly disagree (1) to strongly agree (5).

\subsection{Procedure}

In-house pretesting was adopted by distributing the designed questionnaire to colleagues and experts in the field to comment on the items, structure and layout of the measuring instrument. In addition, pilot testing was used to detect whether weaknesses in the design, measurement and layout of the questionnaire existed, using the same protocols and procedures as that designated for the actual data collection process. Fifteen questionnaires were distributed to various categories of employees, reflecting the demographics of those included in the main study. The pilot subjects confirmed that they understood the instructions, wording of the items and how to use the scale, and that the questionnaire was appropriate in terms of the language-level used.

\subsection{Statistical analyses of the psychometric properties of the questionnaire}

The validity of the questionnaire was statistically analysed using Factor Analysis (Table 1). The Principal Component Analysis was adopted using the Varimax Rotation Method and 6 Factors with latent roots $>1$ were generated. Only items with loadings $>0.5$ were regarded as significant and, when an item was significant on two or more factors, the one with the greatest loading was considered.

Table 1 indicates that sixteen items load significantly onto Factor 1 and account for 11.84 per cent of the total variance in determining job insecurity. Since all sixteen items relate to perceived threats to job features, Factor 1 may be labeled likewise. Furthermore, Table 1 indicates that fifteen items load significantly onto Factor 2 and account for 9.39 per cent of the total variance in determining job insecurity. Since all fifteen items relate to the importance of job features, Factor 2 may be labeled likewise. Table 1 also reflects that fourteen items load significantly onto Factor 3 and account for 9.34 per cent of the total variance. Since all fourteen items relate to the existence of job features, Factor 3 may be labeled as existence of job features. From Table 1 it can be noted that eight items load significantly onto Factor 4 and account for 7.35 per cent of the total variance in determining job insecurity. Since all the items relate to the importance of total job, Factor 4 may be labeled likewise. It is evident from Table 1 that eight items load significantly onto 
Factor 5 and account for 6.52 per cent of the total variance. Since all eight items relate to perceived threats to total job, Factor 5 may be labeled likewise. Table 1 reflects that five items load significantly onto Factor 6 and account for 4.17 per cent of the total variance in determining job insecurity. Two items relate to perceived threats to total job and three items relate to power/powerlessness. Since more items relate to power/powerlessness, Factor 6 may be labeled such, since the three items had moderate to high item loadings.

Table 1

Factor analysis: dimensions of job insecurity

\begin{tabular}{|c|c|c|c|c|c|c|c|c|c|c|c|c|}
\hline & Item & Component & Item & Component & Item & Component & Item & Component & Item & Component & Item & Component \\
\hline & & $\begin{array}{c}1 \\
\text { Perceived } \\
\text { threats to job } \\
\text { features }\end{array}$ & & \begin{tabular}{|c|}
2 \\
Importance \\
of job \\
features
\end{tabular} & & \begin{tabular}{|c|}
3 \\
Existence of \\
job features
\end{tabular} & & \begin{tabular}{|c|}
4 \\
Importance \\
of total job
\end{tabular} & & $\begin{array}{c}5 \\
\text { Perceived } \\
\text { threats to } \\
\text { total job }\end{array}$ & & $\begin{array}{c}6 \\
\text { Power/power } \\
\text { lessness }\end{array}$ \\
\hline & c2 & 0.521 & a2 & 0.540 & b2 & 0.552 & d1 & 0.757 & e1 & 0.707 & e4 & 0.741 \\
\hline & c3 & 0.570 & a4 & 0.670 & b3 & 0.508 & d2 & 0.570 & e2 & 0.662 & e5 & 0.727 \\
\hline & c4 & 0.657 & a5 & 0.562 & b4 & 0.581 & d3 & 0.679 & e3 & 0.665 & f1 & 0.601 \\
\hline & c5 & 0.677 & a6 & 0.663 & b5 & 0.681 & d6 & 0.828 & e6 & 0.819 & f2 & 0.613 \\
\hline & c6 & 0.757 & a7 & 0.694 & b6 & 0.701 & d7 & 0.832 & e7 & 0.826 & f3 & 0.600 \\
\hline & c7 & 0.794 & a8 & 0.756 & b7 & 0.734 & d8 & 0.800 & e8 & 0.715 & & \\
\hline & c8 & 0.765 & a9 & 0.705 & b8 & 0.683 & d9 & 0.798 & e9 & 0.708 & & \\
\hline & c9 & 0.779 & a10 & 0.675 & b9 & 0.663 & d10 & 0.739 & e10 & 0.758 & & \\
\hline & c10 & 0.744 & a11 & 0.597 & b10 & 0.676 & & & & & & \\
\hline & c11 & 0.693 & a12 & 0.644 & b11 & 0.677 & & & & & & \\
\hline & c12 & 0.689 & a13 & 0.514 & b14 & 0.584 & & & & & & \\
\hline & c13 & 0.685 & a14 & 0.653 & b15 & 0.613 & & & & & & \\
\hline & c14 & 0.800 & a15 & 0.651 & b16 & 0.567 & & & & & & \\
\hline & c15 & 0.798 & a16 & 0.669 & b17 & 0.703 & & & & & & \\
\hline & c16 & 0.802 & a17 & 0.684 & & & & & & & & \\
\hline & c17 & 0.812 & & & & & & & & & & \\
\hline $\begin{array}{l}\text { Eigen- } \\
\text { value }\end{array}$ & & 8.761 & & 6.949 & & 6.913 & & 5.435 & & 4.826 & & 3.024 \\
\hline $\begin{array}{l}\% \text { of Total } \\
\text { Variance }\end{array}$ & & 11.84 & & 9.39 & & 9.34 & & 7.35 & & 6.52 & & 4.17 \\
\hline
\end{tabular}

The reliability of the questionnaire was statistically assessed using Cronbach's Coefficient Alpha and indicated a very high level of internal consistency of the items (Alpha $=$
0.901), with item reliabilities ranging from 0.899 to 0.902 (Table 2) and thus reflecting a very high degree of reliability.

Table 2

Cronbach's Coefficient Alpha if item deleted: dimensions of job insecurity

\begin{tabular}{|c|c|c|c|c|c|}
\hline Item & $\begin{array}{c}\text { Cronbach's coefficient } \\
\text { alpha if item deleted }\end{array}$ & Item & $\begin{array}{c}\text { Cronbach's coefficient } \\
\text { alpha if item deleted }\end{array}$ & Item & $\begin{array}{c}\text { Cronbach's coefficient } \\
\text { alpha if item deleted }\end{array}$ \\
\hline a1 & 0.902 & b9 & 0.900 & $\mathbf{c 1 7}$ & 0.899 \\
\hline a2 & 0.902 & b10 & 0.899 & $\mathbf{d 1}$ & 0.900 \\
\hline a3 & 0.901 & $\mathbf{b 1 1}$ & 0.899 & $\mathbf{d 2}$ & 0.900 \\
\hline a4 & 0.901 & $\mathbf{b 1 2}$ & 0.900 & $\mathbf{d 3}$ & 0.900 \\
\hline a5 & 0.900 & $\mathbf{b 1 3}$ & 0.901 & $\mathbf{d 4}$ & 0.901 \\
\hline a6 & 0.900 & $\mathbf{b 1 4}$ & 0.900 & $\mathbf{d 5}$ & 0.901 \\
\hline a7 & 0.900 & $\mathbf{b 1 5}$ & 0.900 & $\mathbf{d 6}$ & 0.900 \\
\hline a8 & 0.900 & $\mathbf{b 1 6}$ & 0.900 & $\mathbf{d 7}$ & 0.900 \\
\hline a9 & 0.900 & $\mathbf{b 1 7}$ & 0.900 & $\mathbf{d 8}$ & 0.900 \\
\hline a10 & 0.900 & $\mathbf{c 1}$ & 0.901 & $\mathbf{d 9}$ & 0.901 \\
\hline
\end{tabular}




\begin{tabular}{|c|c|c|c|c|c|}
\hline a11 & 0.900 & c2 & 0.900 & d10 & 0.900 \\
\hline a12 & 0.900 & c3 & 0.900 & e1 & 0.901 \\
\hline a13 & 0.901 & c4 & 0.900 & e2 & 0.901 \\
\hline a14 & 0.900 & c5 & 0.899 & e3 & 0.901 \\
\hline a15 & 0.900 & c6 & 0.899 & e4 & 0.901 \\
\hline a16 & 0.900 & c7 & 0.899 & e5 & 0.901 \\
\hline a17 & 0.900 & c8 & 0.899 & e6 & 0.900 \\
\hline b1 & 0.900 & c9 & 0.899 & e7 & 0.901 \\
\hline b2 & 0.900 & c10 & 0.899 & e8 & 0.901 \\
\hline b3 & 0.900 & c11 & 0.899 & e9 & 0.901 \\
\hline b4 & 0.900 & c12 & 0.899 & e10 & 0.901 \\
\hline b5 & 0.900 & c13 & 0.899 & f1 & 0.902 \\
\hline b6 & 0.900 & c14 & 0.899 & f2 & 0.902 \\
\hline b7 & 0.900 & c15 & 0.899 & f3 & 0.902 \\
\hline b8 & 0.900 & c16 & 0.899 & & \\
\hline
\end{tabular}

Descriptive statistics (frequency analyses, mean analyses and standard deviations) and inferential statistics (correlations, ANOVA, Post-Hoc Scheffe's Test, t-test) were used to analyse the results of the study.

4

\section{Results of the study}

\subsection{Composition of the sample}

When categorized on the basis of region, the majority of the respondents (63.8 per cent) were from Gauteng while 36.2 per cent were from KwaZulu-Natal. In addition to region, the sample may be classified on the basis of biographical data, that is, age, tenure, race, number of years in current position, educational level and gender. In terms of age, the highest percentage of respondents (42.1 per cent) fell into the age group 30-39 years, followed by 40-49 years ( 36.5 per cent), 50 years and above (12.5 per cent) and 20-29 years ( 8.8 per cent) respectively. The majority of the respondents were in the age group 30-49 years (78.6 per cent). In terms of tenure, 54.5 per cent of the respondents in the company were 16 years of age and above, 28.1 per cent were between 6-10 years of age, 9.3 per cent were between the 0-5 years and 8.1 per cent had been working for the organisation for 11 to 15 years. Further, the majority of respondents were Whites (45.1 per cent), followed by Blacks (28.1 per cent), Indians (19.2 per cent) and then Coloureds (7.6 per cent). When distinguished on the basis of the number of years in their current position, it is evident that 53.8 per cent of the respondents had been in their current position for ten years or more, 23.7 per cent between 7-9 years, 11.9 per cent from 0-3 years and 10.6 per cent for between 4-6 years. In terms of educational qualification, a significant proportion of the respondents had a certificate (33.7 per cent), while 27.4 per cent had matriculation and 24 per cent had a high school qualification. The sample was comprised of 74.3 per cent male respondents and 25.7 per cent female.

\subsection{Descriptive statistics}

Table 3 indicates the descriptive statistics (means, variance, standard deviations, critical values) for each of the sub-dimensions of job insecurity. The greater the mean score value, the greater the extent to which the subdimension existed. However, in the power/ powerlessness sub-dimension of job insecurity, the greater the score value, the greater the extent of power and the less the degree of powerlessness displayed.

Table 3 shows that employees strongly agreed that the job features were very important to them (Mean $=4.28$ ). However, while they believed that these job features existed in their jobs (Mean = 3.54), it is evident that they perceived a high level of threat to these valued features (Mean $=3.25$ ). Likewise, Table 3 reflects that employees felt strongly that their total job was important to them (Mean $=3.88)$. However, they perceived that it was under threat (Mean $=2.88)$. 
Table 3

Descriptive statistics: sub-dimensions of job insecurity

\begin{tabular}{|c|c|c|c|c|}
\hline \multirow{2}{*}{ Sub-dimension of job insecurity } & \multirow{2}{*}{ Mean } & \multirow{2}{*}{$\begin{array}{l}\text { Standard } \\
\text { deviation }\end{array}$} & \multicolumn{2}{|c|}{$95 \%$ Confidence interval for mean } \\
\hline & & & Lower bound & Upper bound \\
\hline The importance of job features & 4.28 & 0.666 & 4.25 & 4.32 \\
\hline Existence of job features & 3.54 & 0.725 & 3.50 & 3.57 \\
\hline Perceived threats of job features & 3.25 & 0.851 & 3.20 & 3.29 \\
\hline Importance of total job & 3.88 & 0.993 & 3.83 & 3.93 \\
\hline Perceived threats of total job & 2.88 & 0.816 & 2.84 & 2.92 \\
\hline Power/Powerlessness & 2.75 & 1.112 & 2.69 & 2.80 \\
\hline
\end{tabular}

In order to assess exactly where employees reflected job importance, perceived threats and experienced feelings of power/powerlessness, frequency analyses were conducted (Table 4):

\section{Table 4}

Frequency analyses: sub-dimensions of job insecurity

\begin{tabular}{|c|c|c|}
\hline Dimension and related statements & & ting \\
\hline Importance of job features & Important (\%) & Very important (\%) \\
\hline A job in which one can tell how well one is doing. & 36.8 & 54.3 \\
\hline Maintaining opportunities to receive periodic pay increases. & 19.6 & 75.2 \\
\hline Maintaining my current level of pay. & 31.1 & 55.3 \\
\hline Existence of job features & Agree & Strongly agree \\
\hline I experience a sense of community in working with good co-workers. & 51.8 & 15.6 \\
\hline I receive feedback from my supervisor regarding my job performance. & 49.3 & 18 \\
\hline The opportunity to do a variety of tasks exists in my job. & 53.4 & 21.9 \\
\hline Existence of job features & Disagree & Strongly Disagree \\
\hline I have promotion opportunities in my current job. & 23.2 & 36.4 \\
\hline Maintaining opportunities to receive periodic pay increases exists in my job. & 14.6 & 12 \\
\hline The status that comes with the position in the organisation exists. & 22.3 & 11.2 \\
\hline My job places physical demands on me. & 51.5 & 22 \\
\hline I have freedom to schedule my own work. & 16.7 & 9.9 \\
\hline Perceived threats of job features & Agree & Strongly agree \\
\hline Negative change is likely to affect my potential to attain pay increases. & 27.2 & 22.5 \\
\hline Negative change is likely to affect my potential to maintain my current pay. & 31.5 & 19 \\
\hline Perceived threats of job features & Disagree & Strongly Disagree \\
\hline Negative change is likely to affect my potential to get ahead in the organisation. & 21.7 & 11.8 \\
\hline $\begin{array}{l}\text { Negative change is likely to affect me in doing an entire piece of work from start to } \\
\text { finish. }\end{array}$ & 24.3 & 6.6 \\
\hline Negative change will affect the variety of the tasks that I perform. & 23.5 & 5.5 \\
\hline $\begin{array}{l}\text { Negative change is likely to affect my current freedom to perform the work in a } \\
\text { manner that I see fit. }\end{array}$ & 24 & 6.2 \\
\hline Importance of total job & Agree & Strongly Agree \\
\hline Not to be laid off from my job even for a short period of time is important to me. & 9 & 12.3 \\
\hline $\begin{array}{l}\text { Not losing my job and not being moved to a lower level within the organisation is } \\
\text { important to me. }\end{array}$ & 22.8 & 42.8 \\
\hline $\begin{array}{l}\text { Being moved to a different job at a higher position in the current location is } \\
\text { important to me. }\end{array}$ & 32.2 & 44.4 \\
\hline $\begin{array}{l}\text { Being moved to a different job at a higher position in another geographical location } \\
\text { is important to me. }\end{array}$ & 34.8 & 35.1 \\
\hline The uncertainty of my department or division's future is important to me. & 23.5 & 45.6 \\
\hline Being laid off permanently is important to me. & 6.5 & 14.9 \\
\hline Being pressured to accept early retirement is important to me. & 7.1 & 11.4 \\
\hline
\end{tabular}




\begin{tabular}{|l|c|c|}
\hline Perceived threats to total job & Agree & Strongly agree \\
\hline A fluctuation in the number of hours worked from day to day is likely to occur. & 32.2 & 11.5 \\
\hline $\begin{array}{l}\text { Losing my job and being moved to another job at the same level within the } \\
\text { organisation is likely to occur. }\end{array}$ & 32 & 12.8 \\
\hline My department or division's future is likely to be uncertain. & 26.4 & 13.2 \\
\hline Losing my job and being laid off permanently is likely to occur. & 21.2 & 10.6 \\
\hline Perceived threats to total job & Disagree & Strongly disagree \\
\hline Being moved to a higher position in another geographic location is likely to occur. & 25.1 & 24.3 \\
\hline Losing my job and being moved to a lower level within the organisation is likely to \\
occur. & 23 & 18.6 \\
\hline Being moved to a higher position within the current location is likely to occur. & 24.1 & 27.7 \\
\hline Losing their job by being fired is likely to occur. & 25.4 & 32 \\
\hline Power/Powerlessness & Agree & Strongly agree \\
\hline I understand the organisation well to control things that affect me. & 32 & 9.9 \\
\hline
\end{tabular}

From the results, it is evident that while the employees experienced a high level of perceived threats to their job features (Mean = 3.25) and a high level of perceived threats to the total job (Mean $=2.88$ ) (Figure 1 and Figure 2), they also reflected a moderate level of powerfulness/powerlessness, which showed their potential for experiencing job insecurity.

\section{Figure 1}

Importance of, existence of and perceived threats to, job features

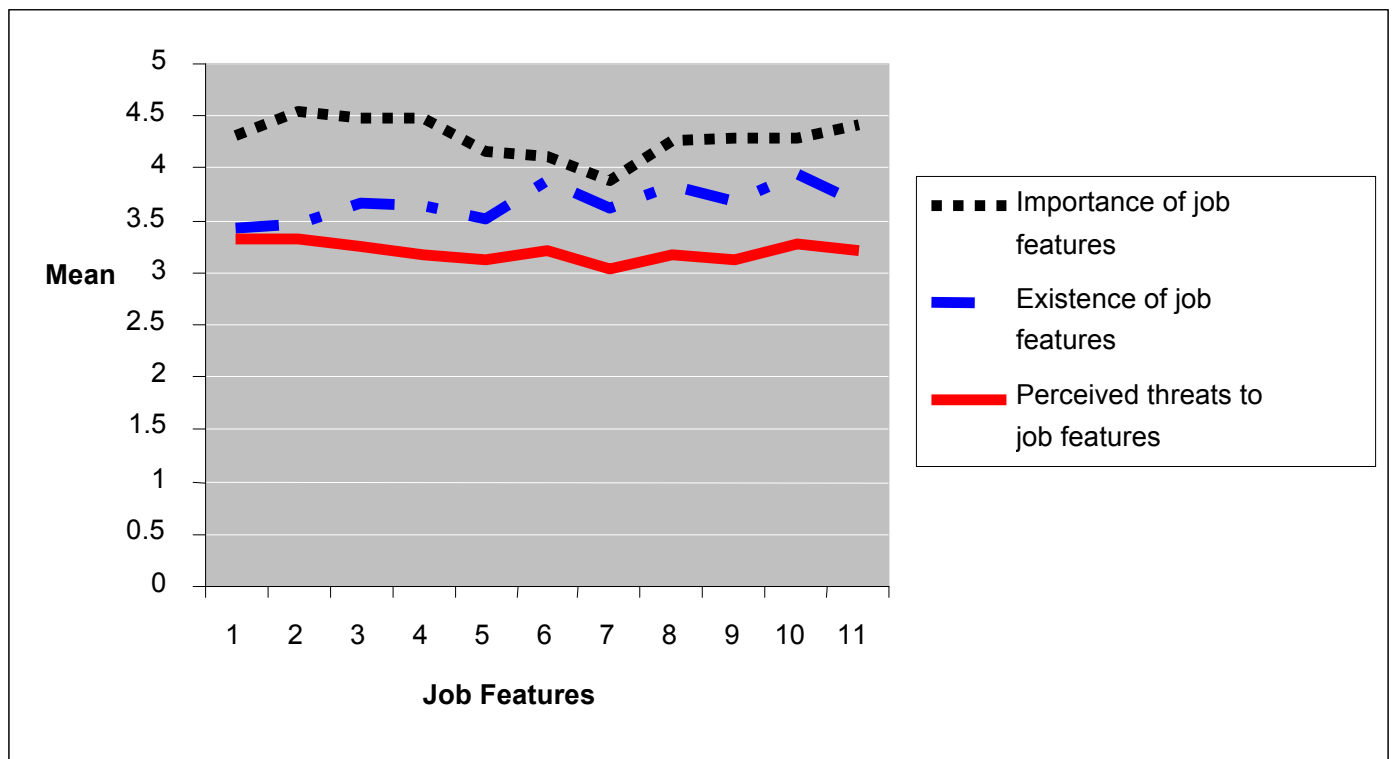

Figure 1 shows that the trend line for the existence of job features is lower than that of the importance of job features, thereby reflecting the potential for unhappiness among employees. Further, the trend line for perceived threats is negligibly lower than that for the existence of job features, thus reflecting the potential for job insecurity. In other words, even the job features that exist are perceived to be under threat, thereby creating the potential for job insecurity.

Figure 2 shows that the trend line for the importance of the total job is rather high. Considering that employees attached a high level of importance to their total job, an abovemoderate level of threat to the total job could 
trigger a high level of job insecurity. Added to this, with the moderate level of power (Mean = 2.75 ) or the moderate level of powerlessness $($ Mean $=2.25)$ experienced, a high proportion of employees felt that they did not hold sufficient power in their organisation to control events that might affect their jobs (Mean = 2.71). This was followed by those who felt that they could not prevent negative things from affecting their work situation in the organisation (Mean $=2.09$ ). Finally, there were those who felt that they did not understand the organisation well enough to be able to control things that affected them (Mean $=1.94)$. This could result in a group of disillusioned employees whose sense of job threat was potentially heightened.

Figure 2

Importance of, and threats to, total job

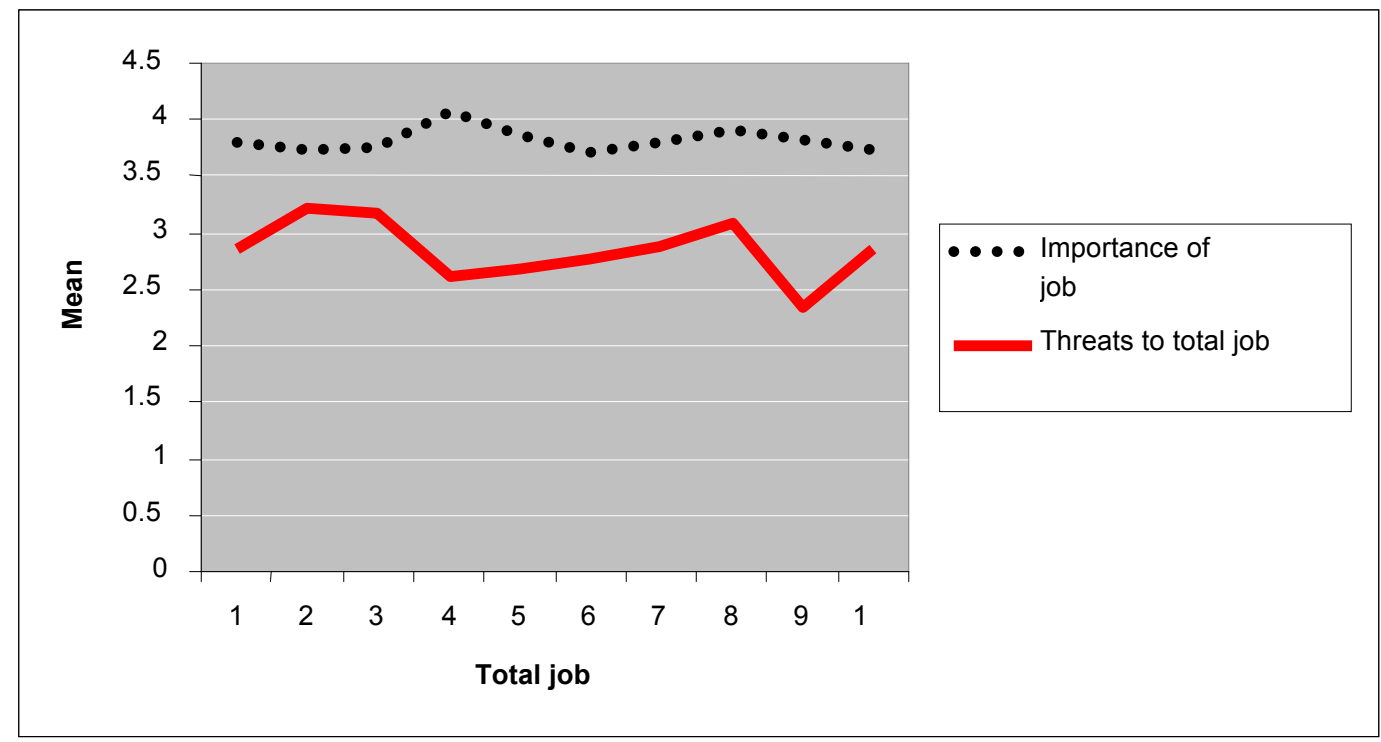

\subsection{Inferential statistics}

Correlation was used to generate the results of the study and make decisions on the hypotheses.

\section{Hypothesis 1}

The items relating to the importance of job features (A) significantly correlate with the existence of these job features (B) and perceived threats to them (C) respectively (Table 5).

Column 3 in Table 5 indicates that the majority of the items relating to the importance of job features correlate significantly with the items relating to the existence of job features at the 1 per cent level of significance. Hence, hypothesis 1 may be partially accepted in terms of the relationships between the items of importance and the existence of job features.
The items where the importance and the existence of job features do not correlate include:

- A2B2, where the Mean of A2 is 4.34 and the Mean of B2 is 2.41, thereby indicating that the importance attached to having promotion opportunities far exceeds the existence of promotion opportunities.

- A4B4, where the Mean of A4 is 4.64 and the Mean of B4 is 3.33, thereby indicating that the importance attached to receiving periodic pay increases exceeds the existence of such opportunities.

Column 6 of Table 5 indicates that the majority of items relating to importance of job features correlate significantly with the items relating to perceived threats to job features at the 1 per cent level of significance. Hence, hypothesis 1 may be partially accepted in 
terms of the relationships between the items relating to the importance of, and threats to, job features. The items for which the importance and the perceived threats of job features do not correlate include:

- A2C2, where the Mean for A2 is 4.34 and the Mean for C2 is 3.16, indicating that while employees attached great importance to promotion opportunities, they felt that these opportunities for advancement were greatly threatened in the organisation.

- A4C4, where the Mean for A4 is 4.64 and the Mean for $\mathrm{C} 4$ is 3.36, reflecting that, while employees attached a very high level of importance to pay increases, they felt that salary increases were, to a great extent, threatened in the organisation.

- A14C14, where the Mean for A14 is 4.27 and the Mean for $\mathrm{C} 14$ is 3.17 , indicating that, while employees attached a high level of importance to doing a variety of tasks, these faced a high level of threat.

- A16C16, where the Mean for A16 is 4.29 and the Mean for $\mathrm{C} 16$ is 3.28, reflecting that, while employees attached a high level of importance to having a job that made a significant impact on others, the significance of their jobs was threatened.

Table 5

Correlation $(r)$ and significance $(p)$ between importance of job features $(A)$, existence of job features (B) and perceived threats to job features (C)

\begin{tabular}{|c|c|c|c|c|c|c|c|c|}
\hline Correlate & $r$ & $p$ & Correlate & $r$ & $p$ & Correlate & $r$ & $p$ \\
\hline A1B1 & 0.143 & $0.000^{*}$ & A1C1 & 0.139 & $0.000^{*}$ & B1C1 & 0.245 & $0.000^{*}$ \\
\hline A2B2 & -0.043 & 0.080 & A2C2 & -0.035 & 0.156 & B2C2 & 0.136 & $0.000^{*}$ \\
\hline A3B3 & 0.205 & $0.000^{*}$ & A3C 3 & 0.058 & $0.020^{* *}$ & В3C3 & 0.076 & $0.002^{*}$ \\
\hline A4B4 & 0.026 & 0.303 & A4C4 & 0.018 & 0.462 & B4C4 & 0.091 & $0.000^{*}$ \\
\hline A5B5 & 0.174 & $0.000^{*}$ & A5C5 & 0.144 & $0.000^{*}$ & B5C5 & 0.149 & $0.000^{*}$ \\
\hline A6B6 & 0.088 & $0.000^{*}$ & A6C 6 & 0.086 & $0.000^{*}$ & B6C6 & 0.223 & $0.000^{*}$ \\
\hline A7B7 & 0.066 & $0.008^{*}$ & A7C7 & 0.076 & $0.002^{*}$ & B7C7 & 0.212 & $0.000^{*}$ \\
\hline A8B8 & 0.064 & $0.010^{*}$ & A8C8 & 0.053 & $0.034^{* *}$ & B8C8 & 0.143 & $0.000^{*}$ \\
\hline A9B9 & 0.222 & $0.000^{*}$ & A9C9 & 0.081 & $0.001^{*}$ & B9C9 & 0.149 & $0.000^{*}$ \\
\hline A10B10 & 0.232 & $0.000^{*}$ & A10C10 & 0.097 & $0.000^{*}$ & B10C10 & 0.175 & $0.000^{*}$ \\
\hline A11B11 & 0.281 & $0.000^{*}$ & A11C11 & 0.142 & $0.000^{*}$ & B11C11 & 0.170 & $0.000^{*}$ \\
\hline A12B12 & 0.336 & $0.000^{*}$ & A12C12 & 0.138 & $0.000^{*}$ & B12C12 & 0.173 & $0.000^{*}$ \\
\hline A13B13 & 0.431 & $0.000^{*}$ & A13C13 & 0.131 & $0.000^{*}$ & B13C13 & 0.156 & 0.000 * \\
\hline A14B14 & 0.141 & $0.000^{*}$ & A14C14 & 0.025 & 0.306 & B14C14 & 0.123 & $0.000^{*}$ \\
\hline A15B15 & 0.197 & $0.000^{*}$ & A15C15 & 0.069 & $0.005^{*}$ & B15C15 & 0.134 & $0.000^{*}$ \\
\hline A16B16 & 0.289 & $0.000^{*}$ & A16C16 & 0.044 & 0.078 & B16C16 & 0.069 & $0.005^{*}$ \\
\hline A17B17 & 0.189 & $0.000^{*}$ & A17C17 & 0.082 & $0.001^{*}$ & B17C17 & 0.107 & $0.000^{*}$ \\
\hline Column 1 & 2 & 3 & 4 & 5 & 6 & 7 & 8 & 9 \\
\hline
\end{tabular}

In these four sets of items, the importance of job features supersedes the perceived threats of job features only negligibly. In such cases, when employees strongly valued job features which faced such a high level of threat, they were more likely to experience job insecurity.

Column 9 in Table 5 indicates that all the items relating to the existence of job features significantly correlated with the items relating to perceived threats to job features, indicating that employees believed that as far as the job features existed, they were equally under threat, signifying the potential for job insecurity. Hence, hypothesis 1 may be accepted in terms of the relationships between the items relating to the existence of, and perceived threats to, job features.

\section{Hypothesis 2}

The items relating to the importance of the total job (D) correlate significantly with the perceived threats to the total job (E) (Table 6). 
Table 6

Correlation ( $r$ ) and significance $(p)$ between importance of total job (D) and perceived threats to total job (E)

\begin{tabular}{|l|c|c|}
\hline \multicolumn{1}{|c|}{ Correlate } & $\mathbf{r}$ & $\mathbf{p}$ \\
\hline D1E1 & 0.313 & $0.000^{*}$ \\
\hline D2E2 & 0.231 & $0.000^{\star}$ \\
\hline D3E3 & 0.291 & $0.000^{*}$ \\
\hline D4E4 & 0.118 & $0.000^{\star}$ \\
\hline D5E5 & 0.203 & $0.000^{\star}$ \\
\hline D6E6 & 0.286 & $0.000^{\star}$ \\
\hline D7E7 & 0.325 & $0.000^{\star}$ \\
\hline D8E8 & 0.343 & $0.000^{\star}$ \\
\hline D9E9 & 0.178 & $0.000^{\star}$ \\
\hline D10E10 & 0.320 & $0.000^{*}$ \\
\hline
\end{tabular}

Columns 2 and 3 in Table 6 indicate that all the items relating to the importance of the total job directly (positive sign of $r$ values in column 2) and significantly correlate with the items relating to perceived threats to the total job. Hence, hypothesis 2 may be accepted. The implication is that the more important the total job, the greater the perceived threat to it, thereby increasing the potential for employee job insecurity.

\section{5}

\section{Discussion}

\subsection{The occurrence and degree of job insecurity}

This study aims first to evaluate the prevalence and magnitude of job insecurity, which was assessed in terms of the perceptions of job features and the total job.

\subsection{Perceptions of job features}

In this study, it is found that the importance of job features (Mean $=4.28)$ is greater than their actual existence (Mean $=3.54$ ), which is greater than perceived threats to job features $($ Mean $=3.25)$, which is greater than power $($ Mean $=2.75)$. It is therefore, evident that the existence of job features is lower than their importance, thereby reflecting the potential for unhappiness among employees. Furthermore, perceived threats to job features are only negligibly lower than the existence of the job features, thus reflecting the potential for job insecurity. This result correlates with the literature overview (De Witte, 2005), which indicated that, for individuals in the organisation, the existence of job features was very low in comparison with the importance they attached to the feature, which left employees feeling dissatisfied. However, certain individuals in the organisation experienced threats to certain job features, some of which did exist, resulting in job insecurity among only those individuals.

\subsection{Perceptions of total job}

In this study, it was found that the importance of the total job (Mean = 3.88) is greater than perceived threats to the total job (Mean $=2.88)$, which is greater than power/ powerlessness $($ Mean $=2.75)$. It is evident that the importance of the total job is rather high. Considering that employees attached a high level of importance to their total job, an abovemoderate level of threats to the total job could trigger a high level of job insecurity among those employees. In addition, there was a moderate level of power $($ Mean $=2.75)$ or powerlessness (Mean $=2.25$ ) experienced, whereby a high proportion of employees felt that:

- they did not have enough power in their organisation to control events that might affect their jobs (Mean = 2.71);

- they could not prevent negative things from affecting their work situation in the organisation $($ Mean $=2.09)$; and

- they did not understand the organisation well enough to be able to control things that affected them $($ Mean $=1.911)$. 
These factors could result in a group of disillusioned employees whose job threat was potentially heightened.

\subsection{Relationships between the dimensions of job features and those of the total job}

This study aims, secondly, to assess the relationships between the sub-dimensions of job features and those of the total job. There is an indication of a significant relationship between the importance of the job features and the existence of the job features and the importance of the total job respectively. The employees believed that the job features that were important to them did exist. The study found that job features were just as important to the employees as the total job. This finding correlates with the literature (Greenhalgh \& Rosenblatt, 1984), which indicated that job features were as important as the total job, because the loss of valued job features represented aspects of job insecurity, but this would be less severe than losing the total job itself.

It was also found that the importance of job features correlated significantly and directly with perceived threats to the job features. The positive sign for the ' $r$ ' value in each of these correlations indicates that as the importance of job features increases so do the perceived threats to them. The study further reflects that the more important the job features are, the greater the degree of perceived threats to the features, creating the potential for job insecurity. This finding correlates with the literature (Boya, Demiral, Ergör, Akvardar \& De Witte, 2008), which reflected that the importance of job features was significantly related to anxiety and depression, indicating higher levels of job insecurity and a greater degree of perceived threats to the job features.

A significant relationship was found between the existence of job features and perceived threats to them. The study further reflects that, although the desired job features did exist, they faced an equal degree of perceived threats, which in turn reflected the potential for job insecurity. These findings correlate with the literature overview (Brun \& Milczarek, 2007; Cambell, Carruth, Dickerson \& Green, 2007; Chovwen \& Ivensor, 2009;).
This reveals that, although the job features did exist, individuals perceived threats to them as a result of organisational restructuring, seeing that these important job features could change or be lost in the new environment.

In this study, as in that by Ugboro and Obeng (2001), it was found that there is no significant relationship between power/ powerlessness and perceived threats to job features.

This study indicates that there is a significant and direct relationship between perceived threats to job features and perceived threats to the total job. The positive sign for the ' $r$ ' value in each of these correlations indicates that, as threats to job features increase, so do the threats to the total job and vice-versa. This study found further that there was a significant and direct relationship between the importance of the total job and perceived threats to total job. This indicates that the greater the importance of total job, the greater the perceived threats to it, which increases the potential for intensified job insecurity. Similar findings were obtained in the literature overview (Ugboro \& Obeng, 2001).

This study also found that there was a significant but inverse relationship between power/powerlessness and perceived threats to the total job. This indicates that the greater the perceived threats to total job, the less the feeling of power (the greater the feeling of powerlessness), thereby increasing the level of employee job insecurity experienced.

\subsection{Implications for job insecurity}

From the results of the study, it is evident that:

- When an increase in the importance attached to job features corresponds to an increase in existence of job features (that is, a significant and direct relationship exists), the potential for job insecurity is reduced.

- When an increase in the importance attached to job features corresponds to an increase in the perceptions of threats to these job features (that is, a significant and direct relationship exists), the potential for job insecurity increases.

- When an increase in the perceived existence of job features corresponds to an increase in perceptions of threats to job 
features (that is, a significant and direct relationship exists), the potential for job insecurity increases.

- When an increase in the importance of the total job corresponds to an increase in the perceptions of threats to the total job (that is, a significant and direct relationship exists), the potential for job insecurity increases.

\section{6}

\section{Conclusions and recommendations}

The high level of importance of job features and the importance of the total job displayed reflects that employees do not carry out a job simply for the sake of doing so. Employees attach value to the job features and to their total job. It is therefore important for organisations to ensure the existence of these job features and to minimise or reduce threats to these and to the total job. After all, organisations have the potential to reduce any feelings of job insecurity. When employees attach a high level of importance to their job features, perceiving threats to them, as well as experiencing feelings of powerlessness, they become susceptible to job insecurity. Specifically, in an organisation undergoing major restructuring, it is imperative for change managers to:

$\checkmark$ Close the gap between the importance of job features and perceived threats to job features by:

- Providing regular feedback on performance.

- Ensuring sustainable pay progression.

- Encouraging social association.

- Providing task variety.

- Creating more training opportunities.

- Creating more promotion opportunities.

- Implementing the strategy of empowerment by, for example, allowing employees the freedom to schedule their own work.

- Being sensitive to issues of redeployment.

- Providing regular and precise information regarding the process of transformation.

- Ensuring effective, open and transparent communication before, during and after the process of transformation. $\checkmark$ They could close the gap between the importance of the total job and perceived threats to it by:

- Providing promotion opportunities in the organisation and in other geographical regions of the organization.

- Constantly updating employees on changes in the organization.

- Being cautious about issues of retrenchment and dismissal.

- Finding alternatives to employee retrenchment, for example, by making use of early retirement options.

- Maintaining consistency in working hours/ shifts.

- Considering employees' perceptions.

- Ensuring the effective management of conflict, negotiation, perceived fairness and job design.

- Encouraging creativity.

- Providing clear direction, vision and mission of the organisation, in the process focusing on individual role clarity and how each employee will contribute to the vision and mission.

- Develop strategies to reduce feelings of powerlessness and enhance feelings of power.

- Encourage employee participation, especially when it comes to issues of work scheduling and work methods.

- Ensure open channels of communication.

- Provide employees with opportunities for decision-making and problem-solving.

\section{Delimitations and suggestions for future} research

Due to the lengthy duration of any major restructuring process, it would be valuable in future studies relating to job insecurity in any organisation undergoing transformation to assess the prevalence and magnitude of job insecurity by using a longitudinal time frame rather than the cross-sectional one used in this study. In this way, comparisons could be made before, during and after the process of transformation. Such an approach would enable the researcher to assess whether differences in the magnitude of job insecurity during a period of major change existed and when it was at its peak. 


\section{Acknowledgement}

The authors are grateful to the reviewers for constructive comments and motivation.

\section{References}

ASHFORD, S.J., LEE, C. \& BOBKO, P. 1989. Content, causes and consequences of job insecurity: a theorybased measure and substantive test. Academy of Management Journal, 32(4):803-829.

BARLING, J. \& KELLOWAY, E.K. 1996. Job insecurity and health: the moderating role of workplace control. Stress and Medicine, 12:253-259.

BOHLE, P., QUINLAN, M. \& MAYHEW, C. 2001. The health effects of job insecurity: An evaluation of the evidence. Economic and Labour Review, 12(1):32-60.

BORG, I. \& ELIZUR, D. 1992. Job insecurity: correlates, moderators and measurement. International Journal of Manpower, 13(2):13-26.

BOYA, F.Ö., DEMIRAL, Y., ERGÖR, A., AKVARDAR, Y. \& DE WITTE, H. 2008. Effects of perceived job insecurity on perceived anxiety and depression in nurses. Industrial Health, 46(6):613-619.

BROCKNER, J., GROVER, S., REED, T.F. \& DE WITTE, E.L. 1992. Layoffs, job insecurity, and survivor's work effort: evidence of an inverted-U relationship. Academy of Management Journal, 35(2): 413-425.

BRUN, E. \& MILCZAREK, M. 2007. Expert forecast on emerging psychosocial risks related to occupational safety and health. European Agency for Safety and Health at Work, Luxembourg: Office for official publications of the European communities.

BURKE, R.J. \& COOPER, C.L. 2000. The organisation in crisis: downsizing, restructuring and privatisation. Oxford, England: Blackwell Publishing.

BURKE, R.J. \& NELSON, D. 1998. Mergers and acquisitions, downsizing and privatization: A North American Perspective. In Gowing, M.K., Kraft, J.D., Qiu, J.C. The new organisational reality: downsizing, structuring and revitalization American Psychological Association Washington, D.C.

CAMBELL, D., CARRUTH, A., DICKERSON, A. \& GREEN, F. 2007. Job insecurity and wages. The Economic Journal, 117(518):544-566.

CAPLAN, R.D., COBB, S., FRENCH, J.R.P., VAN HARRISON, R.V. \& PINNEAU, S.R. 1980. Job demands and worker health: main effects and occupational differences. Ann Arbor: Survey Research Centre, Institute of Social Research, University of Michigan.

CHOVWEN, C. \& IVENSOR, E. 2009. Job insecurity and motivation among women in Nigerian consolidated banks. Gender in Management: An International Journal, 24(5):316-326.

DAVY, K.A., KINICKI, A.J. \& SCHECK, C.L. 1997. A test of job insecurity's directed and mediated effects on withdrawal cognition. Journal of Organisational Behaviour, 18(4):323-349.

DEKKER, S.W. \& SCHAUFELI, W.B. 1995. The effects of job insecurity on psychological health and withdrawal: a longitudinal study. Australian Psychologist, 30:57-63.

DE WITTE, H. 1999. Job insecurity and psychological well-being: review of the literature and exploration of some unresolved issues. European Journal of Work and Organizational Psychology, 8(2):155-177.

DE WITTE, H. 2005. Job insecurity: review of the International Literature on definitions, prevalence, antecedents and consequences. Journal of Industrial Psychology, 31(4):1-6.

DUNLAP, J.C. 1994. Surviving layoffs: a qualitative study of factors affective retained employees after downsizing. Performance Improvement Quarterly, 7(4):89-113.

FERRIE, J.E. 1997. Labour market status, insecurity and health. Journal of Health Psychology, 2: 155-170.

FORBES, D. 1985. The no-layoff payoff. Dun's Business Month, 126(1):64-66.

GREENHALGH, G.L. \& ROSENBLATT, Z. 1984. Job insecurity: toward conceptual clarity. Academy of Management Review, 9(3):438-448.

HARTLEY, J., JACOBSON, D., KLANDERMANS, B. \& VAN VUUREN, T. 1991. Job insecurity. London: Sage Publications.

HEANEY, C.A., ISRAEL, B.A. \& HOUSE, J.S. 1994. Chronic job insecurity among automobile workers: effects on job satisfaction and health. Social Science and Medicine, 38:1431-1437. 
HELLGREN, J., SVERKE, M. \& ISAKSSON, K. 1999. A two-dimensional approach to job insecurity: consequences for employee's attitudes and well-being. European Journal of Work and Organisational Psychology, 8(2):179-195.

ISAKSSON, K., HELLGREN, J. \& PETTERSSON, P. 2000. Repeated downsizing: attitudes and wellbeing for surviving personnel in a Swedish retail company. In Isaksson, K.; Hogstedt, C.; Eriksson, C. \& Theorell, T. (eds.) Health Effects of the New Labour Market New York: Kluwer/Plenum Press 85-101.

ITO, J.K. \& BROTHERIDGE, C.M. 2007. Exploring the predictors and consequences of job insecurity's components. Journal of Managerial Psychology, 22(10):40-64.

KIM, W. 2003. Economic crisis, downsizing and 'layoff survivor's syndrome. Journal of Contemporary Asia, 33(4):449-464.

KIVIMAKI, M., VAHTERA, J., PENTTI, J., THOMSON, L., GRIFFITHS, A. \& COX, T. 2001.

Downsizing changes in work, and self-rated health of employees: A 7-year panel 3-wave panel study. Anxiety, Stress and Coping, 14:59-73.

LORD, A. \& HARTLEY, J. 1998. Organisational commitment and job insecurity in a changing public service organisation. European Journal of Work and Organisational Psychology, 7(3):341-354.

MAUNO, S. \& KINNUNEN, U. 1999. Job insecurity and well-being: a longitudinal study among male and female employees in Finland. Community, Work and Family, 2(2):147-171.

MAUNO, S., KINNUNEN, U., MAKIKANGAS, A. \& NATTI, J. 2005. Psychological consequences of fixed-term employment and perceived job insecurity among health care staff. European Journal of Work and Organizational Psychology, 14(3):209-237.

MOHREN, D., SWAEN, G., VAN AMELSVOORT, L., BORM, P. \& GALAMA, J. 2003. Job insecurity as a risk factor form common infections and health complaints. Journal of Occupational and Environmental Medicine, 45(2):123-129.

PEPPER, L., MESSINGER, M., WEINBERG, J. \& CAMPBELL, R. 2003. Downsizing and health in the United States Department of Energy. Journal of Industrial Medicine, 44:481-491.

PROBST, T.M. 2003. Exploring employee outcomes or organisational restructuring: A Solomon four-group study. Group and Organization Management, 28:416-439.

PROBST, T.M. \& BRUBAKER, T.L. 2001. The effects of job insecurity on employee safety outcomes: cross-sectional and longitudinal explorations. Journal of Occupational Health Psychology, 6(2):139-158.

QUINLAN, M. 2007. Organisational restructuring/downsizing, OHS regulation and worker health and wellbeing. Working Paper 52, Regulatory Institutions Network: National Research Centre for OHS Regulation.

ROMZEK, B.S. 1985. The effects of public service recognition, job security and staff reductions on organisational involvement. Public Administration Review, 45(2):282-292.

SEKARAN, U. 2003. Research methods for business: a skill building approach. (4 ${ }^{\text {th }}$ ed.) USA: John Wiley and Sons, Inc.

STRAZDINS, L., D’SOUZA, R., LIM, L, BROOM, D. \& RODGERS, B. 2004). Job strain, job insecurity, and health: rethinking the relationship. Journal of Occupational Health Psychology, 9(4):296-305.

SVERKE, M. \& HELLGREN, J. 2002. The nature of job insecurity: understanding employment uncertainty on the brink of a new millennium. Applied Psychology: An International Review, 51(1):23-42.

SVERKE, M., HELLGREN, J. \& NÄSWALL, K. 2002. No security: a meta-analysis and review of job insecurity and its consequences. Journal of Occupational Health Psychology, 7(1):242-264.

TETRICK, L.E. \& QUICK, J.C. 2003. Prevention at work: public health in occupation settings: Handbook of occupational health psychology. American Psychological Association Washington, D.C.

UGBORO, I.O. \& OBENG, K. 2001. Managing the aftermaths of contracting in public transit organizations: employee perception of job insecurity, organizational commitment and trust. Greenboro, USA: North Carolina A\&T State University.

WESTMAN, M., ETZION, D. \& DANON, E. 2001. Job insecurity and crossover of burnout in married couples. Journal of Organizational Behaviour, 22:467-481.

YOUSEF, D.A. 1998. Satisfaction with job insecurity as a predictor of organisational commitment and job performance in a multicultural environment. International Journal of Manpower, 19(3):184-194. 